\title{
REVIEW
}

\section{Botulinum Toxins for Facial Lines: A Concise Review}

Nicholas J. Lowe $\cdot$ Philippa Lowe

To view enhanced content go to www.dermtherapy-open.com Received: April 20, 2012 / Published online: September 29, 2012

(c) The Author(s) 2012. This article is published with open access at Springerlink.com

\section{ABSTRACT}

This is a concise review of the uses of botulinum toxins (BTXs) in dermatology and cosmetic procedures. It is a clinical rather than a basic science, pharmacological review. BTX had been initially used for selectively reducing and balancing periorbital muscle activity; thereby, reducing childhood strabismus and blepharospasm. This clinical research was initiated by Dr. Alan Scott over 40 years ago. BTX type A (BTX-A) was serendipitously observed to reduce forehead frown lines in patients being treated for blepharospasm. Extensive clinical research and development resulted in widespread aesthetic uses for BTX-A

N. J. Lowe $(\bowtie) \cdot$ P. Lowe

The Cranley Clinic, 3 Harcourt House,

19a Cavendish Square, London W1G OPN, UK

e-mail: cranley@cranleyclinic.com

N. J. Lowe

UCLA School of Medicine, Los Angeles, CA, USA

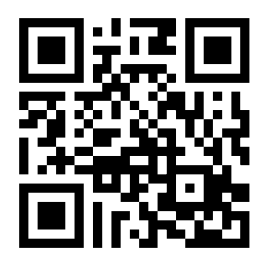

Enhanced content for this article is

available on the journal web site:

www.dermtherapy-open.com by reduction of selected hyperfunctional facial muscles. BTXs are also used for reduced localized hyperhidrosis. A topical BTX-A is being developed as a potential alternative to injected BTX.

Keywords: Axillary hyperhidrosis; Botulinum toxins; Combination treatment; Dermatology; Facial lines; Periocular muscles; Strabismus

\section{INTRODUCTION}

The first medical use of botulinum neurotoxin (BTX) was described by Dr. Alan Scott during the 1970s, when BTX type A (BTX-A) was used for reducing over-activity of selected periocular muscles in patients with strabismus $[1,2]$. Following this observation, BTXs have been increasingly studied for a wide variety of other therapeutic and aesthetic uses. In the late 1980s, Drs. Jean and Alastair Carruthers observed a reduction of dynamic lines on the forehead of a patient being treated for blepharospasm. They reported their observation in 1992 [3]. Double-blind, placebo-controlled studies using BTX-A for 
upper facial lines in the USA confirmed their reduction of lower forehead lines for approximately 4 months [4, 5].

These initial observations were followed by double-blind, placebo-controlled studies of several hundred patients in the USA, which demonstrated that BTX-A was safe and effective for reducing the severity of glabellar (lower forehead vertical frown lines) $[6,7]$. A significant improvement was observed a few days after treatment and the mean duration of treatment was in excess of 4 months. This study utilized appropriate doses of onabotulinumtoxinA, with a total of 20 onabotulinumtoxinA units for the lower forehead frown lines. Other studies confirmed that BTX-A is also effective for lateral periorbital lines [8], infraorbital lines [9], nasal lines, terional area, the jaw line, and the platysma.

\section{BTXS}

There are two main serotypes of BTXs that are used clinically; the most commonly used being BTX-A. BTX type B (BTX-B) has a much shorter duration of effect than BTX-A, but is occasionally used if therapeutic resistance to BTX-A is observed [10]. BTX-A and -B are also effective at reducing sweating in areas such as the axillae $[11,12]$. BTX-A treatment for axillary hyperhidrosis has been approved in numerous countries in addition to the USA. A recent study of hyperhidrosis found that the benefit of duration of BTX-B was longer to that seen after intramuscular treatment, but still less than BTX-A [13].

The transport of the BTX-A is by rapid uptake of the light chain of the toxin into the neuromuscular junction, and the presynaptic inhibition of acetylcholine release is thought to be one mode of action of BTX-A (Fig. 1). As a result, BTX-A results in localized, reversible muscle relaxation (1). Some facial lines result from repetitive contraction of facial muscles and, as BTX-A reduces muscle action, one cause of facial lines is, thus, reduced [4-7].

For the treatment of hyperhidrosis, BTX-A activity is the result of the inhibition of the release of acetylcholine, a neurotransmitter that controls emotional, non-thermoregulatory sweating $[11,12]$. However, one of the practical problems with BTX-A treatment is its variable duration of benefit against hyperhidrosis. Those patients that have a long duration of benefit (i.e., 9 months or longer) find the treatment worthwhile, whilst those with short duration (i.e., 4 months or less) are less inclined to continue.

\section{FACIAL INJECTION SITES FOR BTX-A}

The sites of injection used to improve facial lines and, therefore, some signs of facial aging are (Figs. 2, 3, 4, 5, 6, 7): (A) upper face: horizontal forehead lines, vertical forehead lines, supraorbital lines, periorbital (crow's feet) lines, infraorbital lines, and paranasal lines [13]; (B) lower face: perioral lines, vertical rhytids above the upper lip, and turning down of the angles of the mouth (melomental folds) from depressor angulae oris muscle; (C) vertical neck bands produced by platysmal muscle activity can also be reduced with BTX-A [14].

\section{DIFFERENT TYPES OF BTX-A}

Two different commercial types of BTX-A have been available in Europe since the 1990s. The two types are produced by different bacteria with differing fermentation and purification processes, and also have different potency and diffusion. The dilution and dosing have been 


\section{BTX Blocks Acetylcholine Release}

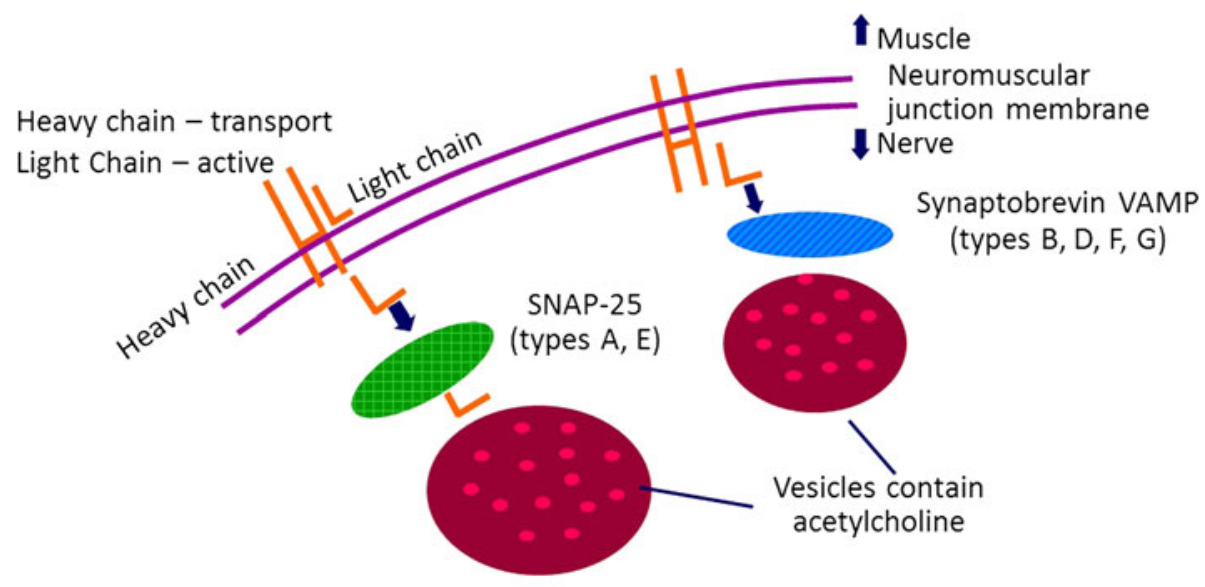

Light chains target and proteolyses

SNARE proteins (eg, SNAP-25) Blocks acetylcholine release

Fig. 1 Possible mode of action of BTX-A. BTX-A botulinum toxin type A, $S N A P-25$ synaptosomal-associated protein 25 , $S N A R E$ SNAP receptor, $V A M P$ vesicle-associated membrane protein

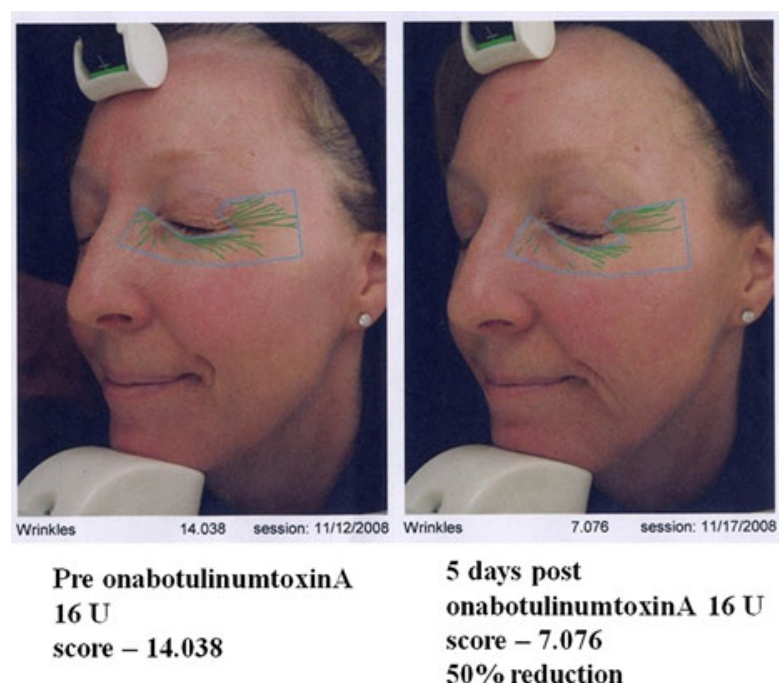

Fig. 2 Onset of action of onabotulinumtoxinA

investigated, and estimated conversion ratios of one type of BTX-A to the other have been proposed $[15,16]$. This has been purified by a propriety process to remove inactive proteins. More recently, incobotulinumtoxinA has been available in Europe.

Side effects from BTX-A are local at doses used for aesthetic indications, e.g., bruising, and brow

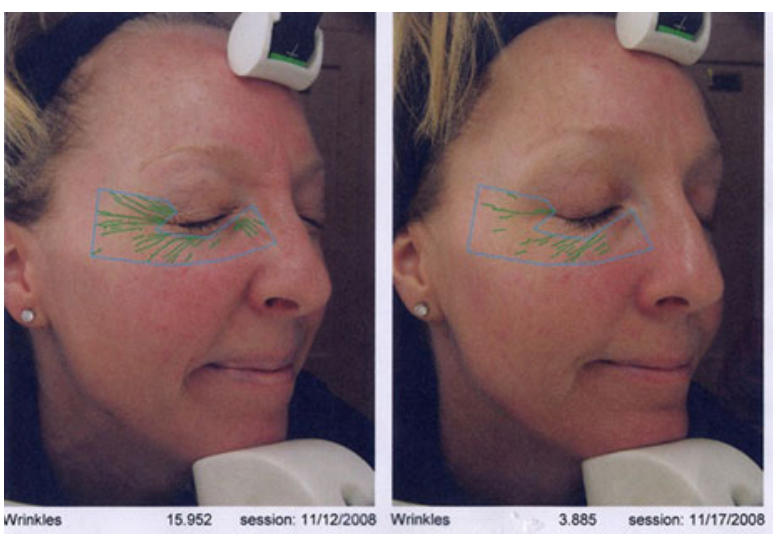

Pre

5 days post

abobotulinumtoxinA abobotulinumtoxin A $48 \mathrm{U}$ $48 \mathrm{U}$ score -3.385

score $-15.952 \quad 79 \%$ reduction

Fig. 3 Onset of action of abobotulinumtoxinA

and/or eyelid ptosis. Side effects are usually the result of inexpert injection of BTX-A, for example, injections of too high a dose of BTX-A to the lower lateral forehead may result in both brow ptosis as well as upper eyelid ptosis. Injections too low to the infraorbital area may result in upper lip and lower facial ptosis. Facial asymmetry may also occur; these side effects are 


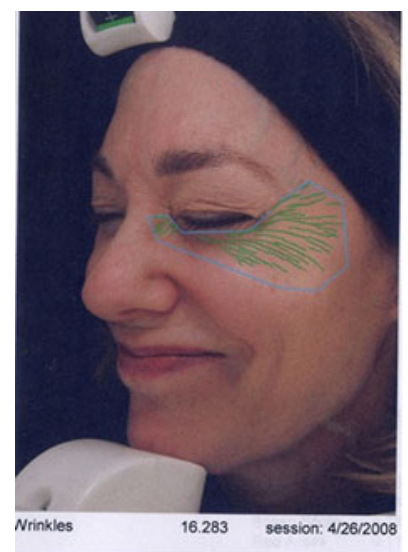

Pre

onabotulinumtoxin $\mathrm{A}$

16 Units

Wrinkle score $-\mathbf{1 6 . 2 8 3}$

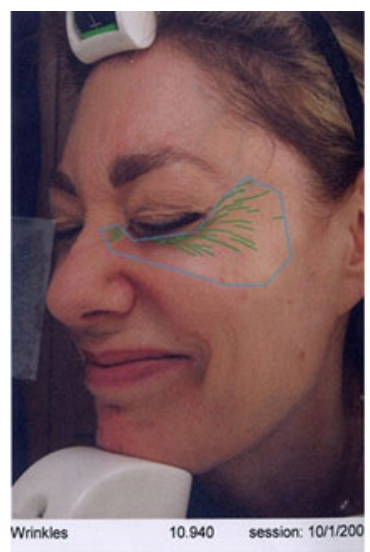

6 months post onabotulinumtoxin $\mathrm{A}$

Wrinkle score $\mathbf{- 1 0 . 9 4 0}$ $32 \%$ wrinkle reduction
Fig. 4 Duration of benefit of onabotulinumtoxinA can be measured 6 months post-treatment

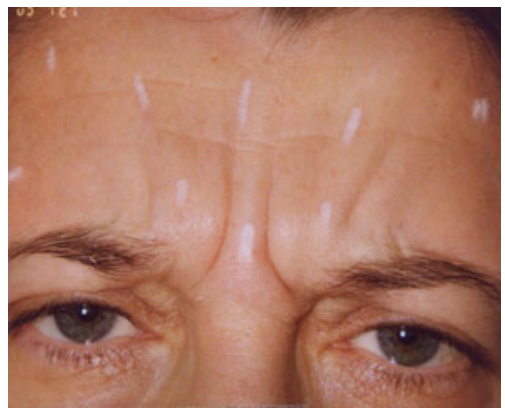

Fig. 5 Selection of toxin based on clinical features. This patient has focal deep glabellar lines and requires brow elevation. The patient was a good candidate for onabotulinumtoxin $\mathrm{A}$, which was given at 2 and 4 units per site $(\times 10)$ resulting in a total of 32 units administered

usually temporary but can be of understandable concern to patients [17]. Rare side effects include headaches, paraesthesia, muscle and brow "heaviness," diplopia, dry eyes, dysphagia, and dysarthria. The physician injecting BTX-A should be trained to try to avoid and correct these problems.

Resistance to BTX-A is a rare problem and the mechanism is unknown, but may involve

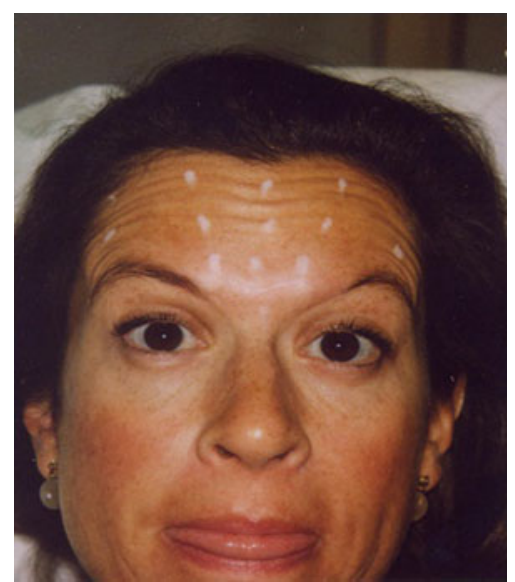

Fig. 6 Selection of toxins based on clinical features. This patient has a broad forehead, transverse lines but no brow elevation is required. The patient was a good candidate for abobotulinumtoxin $\mathrm{A}$, which was given at 5 and 10 units per site, resulting in a total of 115 units administered

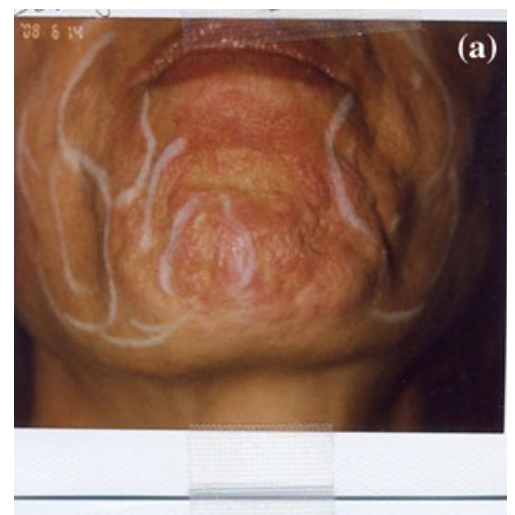

(b)

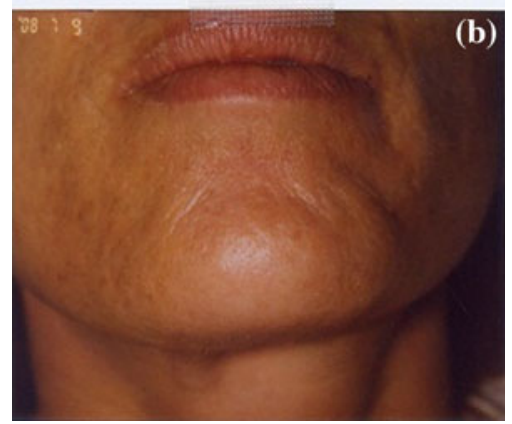

Fig. 7 A lower facial indication for BTX-A. a This patient had mentalis dimples for which 15 units of abobotulinumtoxin A was administered to the mid mentalis. b The same patient 4 weeks post-treatment. $B T X-A$ botulinumtoxin A 
antibodies blocking the uptake or action of BTX-A. The incidence of acquired resistance is currently not determined. BTX-B can be used in cases of therapeutic resistance.

\section{COMBINATION TREATMENTS WITH BTX-A}

Combination treatments are selected for appropriate patients to rejuvenate the aging face [17]. Examples of these combinations include administration of BTX-A prior to laser treatment with resurfacing lasers [17] or fractionated lasers (Figs. 8, 9). BTX-A is ideally delivered at least 1 week prior to laser treatment, which enables the hyperactive muscle action to be reduced; thereby, reducing the cause of facial lines. In addition, as one theory of skin rejuvenation with these laser systems is the stimulation of neocollagenesis, it is likely that less-folded skin following BTX-A leads to more uniform neocollagenesis [18].

Other situations where combination treatments are useful is the combination of BTX-A and dermal fillers in problems such as deep vertical lower forehead lines. Here, BTX-A alone will improve, but not clear, the deep
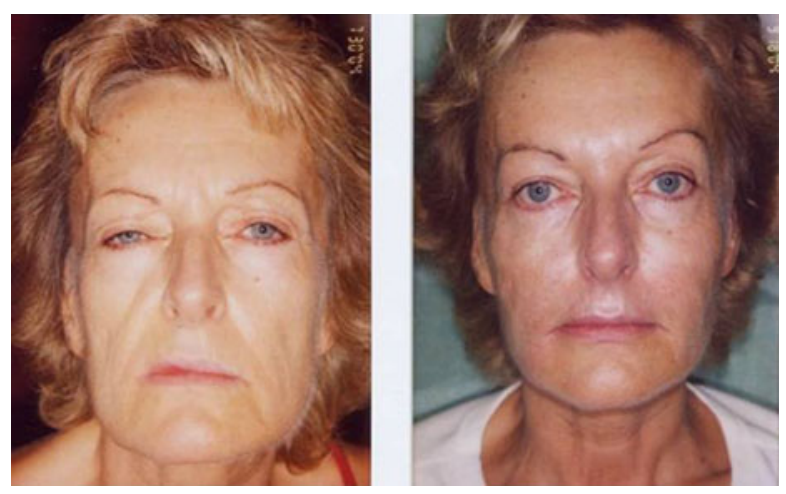

Fig. 8 Combination of treatments: hyaluronic filler in the upper cheeks, lips; polylactic acid over the lower face; BTX-A in the forehead, crow's feet, and neck; fractional laser treatment to the face and neck. BTX-A botulinumtoxin $\mathrm{A}$
A summary of how to incorporate BTX-A in a treatment programme: COMBINE BTX-A?

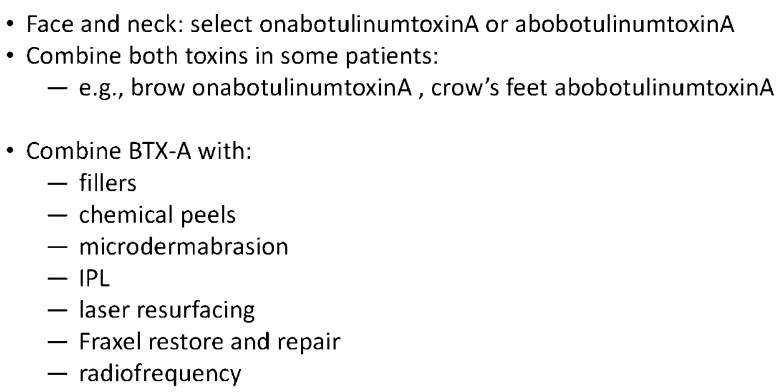

Fig. 9 A summary of how to incorporate BTX-A in a treatment program. $B T X-A$ botulinum toxin $\mathrm{A}, I P L$ intense pulsed light

furrows that are present in some patients. The use of BTX-A plus temporary fillers can give a more prolonged effect than using the filler alone [19]. Similarly, the use of BTX-A to the upper lip area together with a filler in the upper lip can provide an adjunctive benefit to the correction of upper lip lines. Dermal fillers and BTX-A can also be combined in lower facial areas where the BTX-A is injected into areas such as the depressor angulae oris and mentalis muscles, and the filler injected into melomental folds.

\section{RECENT QUANTITATIVE STUDIES OF BTX-A FOR FACIAL LINES}

In the UK, onabotulinumtoxinA and abobotulinumtoxinA have been used for approximately 20 years. Results from quantitative studies show that the onset and duration of benefit is variable when different BTXs are compared [20]. This is not surprising, as different BTXs are individual molecules with different molecular weights. It has been shown that onabotulinumtoxinA and abobotulinumtoxinA have similar benefits, although in a recent study, abobotulinumtoxinA was found to be slightly (at a 1:3 ratio) more efficient than onabotulinumtoxinA for crow's feet [21]. 
Table 1 Molecular characteristics and approvals of botulinum toxins

\begin{tabular}{lllllll}
\hline Product & $\begin{array}{l}\text { Toxin } \\
\text { type }\end{array}$ & $\begin{array}{l}\text { Molecular } \\
\text { weight } \\
(\mathbf{k D a})\end{array}$ & $\mathbf{p H}$ & $\begin{array}{l}\text { Approved for } \\
\text { forehead lines }\end{array}$ & $\begin{array}{l}\text { Approved for } \\
\text { hyperhidrosis }\end{array}$ & $\begin{array}{l}\text { Approved for } \\
\text { medical indications, } \\
\text { e.g., } \\
\text { cervical } \\
\text { dystonia, } \\
\text { blepharospasm }\end{array}$ \\
\hline onabotulinumtoxinA & A & 900 & $\sim 7$ & EU + USA & EU + USA & EU + USA \\
abobotulinumtoxinA & A & $500-900$ & $\sim 7$ & EU + USA & No & EU + USA \\
incobotulinumtoxinA & A & 150 & $\sim 7$ & EU & No & EU \\
rimabotulinumtoxinB & B & $700-900$ & 5.6 & No & No & EU + USA \\
\hline
\end{tabular}

More recently, incobotulinumtoxinA has been approved for dystonia. Further studies are required to assess comparative efficacies of incobotulinumtoxinA and onabotulinumtoxinA. A recent study suggested the equivalent efficacy of 1 unit of onabotulinumtoxinA to 1 unit of incobotulinumtoxinA; however, this was only a 12 week study [22] and further comparisons would be desirable.

\section{DIFFERENT BTXS APPROVED IN EUROPE AND USA}

A comparison of molecular characteristics and product approvals of BTXs can be seen in Table 1, and myths and truths in Fig. 10.

BTX-A; some MYTHS and TRUTHS

Myth - TAKES a WEEK TO WORK

Truth - Onset: Abo-A $12 \mathrm{~h}$, Ona-A $48 \mathrm{~h}$

Full: $\quad$ Abo-A 3 days, Ona-A 5 days

Myth - ONLY LASTS 3-4 MONTHS

Truth - Effects detected up to 6 months, if measured accurately

Myth - BTX-A is a FRAGILE MOLECULE

Truth - Mechanical SHAKING at room temperature for 6 WEEKS caused NO loss of efficacy in mouse assay

Fig. 10 Myths and truths of BTX-A. $A b o-A$ abobotulinumtoxinA, BTX-A botulinum toxin A, Ona-A onabotulinumtoxinA

\section{TOPICAL BTX}

Topical BTXs continue to be investigated mainly in Mexico and North America. A novel gel delivery system is also available, which has been developed for delivering a $150 \mathrm{kDa}$ BTX-A formulation (developed by Revance Therapeutics, Inc., Newark, CA, USA) Studies have so far mainly focused on treating axillary hyperhidrosis and crow's feet areas [23], with this formulation showing effective and very promising results. Studies comparing the efficiency and duration compared with injectable BTX-A will be of interest.

\section{CONCLUSION}

BTX-A is a safe and effective treatment for the reduction of hyperfunctional facial muscles that cause facial lines. In addition, it is also a treatment option for the control of localized hyperhidrosis.

\section{ACKNOWLEDGMENTS}

Dr. Lowe is the guarantor for this article, and takes responsibility for the integrity of the work as a whole. 
Conflict of interest. The authors declare no current conflict of interest for this manuscript.

Open Access. This article is distributed under the terms of the Creative Commons Attribution Noncommercial License which permits any noncommercial use, distribution, and reproduction in any medium, provided the original author(s) and the source are credited.

\section{REFERENCES}

1. Scott AB, Rosenbaum A, Collins CC. Pharmacologic weakening of extraocular muscles. Invest Ophthalmol. 1973;12:924-7.

2. Scott AB. Botulinum toxin injection into extraocular muscles as an alternative to strabismus surgery. Ophthalmology. 1980;87:1044-9.

3. Carruthers JD, Carruthers JA. Treatment of glabellar from lines with C. botulinum-A exotoxin. J Dermatol Surg Oncol. 1992;18:17-21.

4. Keen M, Blitzer A, Aviv J, et al. Botulinum toxin A for hyperkinetic facial lines: results of a doubleblind, placebo-controlled study. Plast Reconstr Surg. 1994;94:94-9.

5. Lowe NJ, Maxwell A, Harper H. Botulinum A exotoxin for glabellar folds: a double-blind, placebo-controlled study with an electromyographic injection technique. J Am Acad Dermatol. 1996;35:569-72.

6. Carruthers JA, Lowe NJ, Menter MA, for the BOTOX Glabellar Lines I Study Group, et al. A multicenter, double-blind, randomized, placebo-controlled study of the efficacy and safety of botulinum toxin type $\mathrm{A}$ in the treatment of glabellar lines. J Am Acad Dermatol. 2002;46:840-9.

7. Carruthers JD, Lowe NJ, Menter MA, Gibson J, Eadie $\mathrm{N}$, for the BOTOX Glabellar Lines II Study Group, et al. Double-blind, placebo-controlled study of the safety and efficacy of botulinum toxin type A for patients with glabellar lines. Plast Reconstr Surg. 2003;112:1089-98.

8. Lowe NJ, Ascher B, Heckmann M, Kumar C, Fraczek $\mathrm{S}$, for the Botox Facial Aesthetics Study Team. Double-blind, randomized, placebo-controlled, dose-response study of the safety and efficacy of botulinum toxin type A in subjects with crow's feet. Dermatol Surg. 2005;31:257-62.
9. Flynn TC, Carruthers JA, Carruthers JA, Clark RE II. Botulinum A toxin (BOTOX) in the lower eyelid: dose-finding study. Dermatol Surg. 2003;29:943-50.

10. Lowe NJ, Yamauchi PS, Lask GP, Patnaik R, Moore D. Botulinum toxin types A and B for brow furrows: preliminary experiences with type B toxin dosing. J Cosmet Laser Ther. 2002;4:15-8.

11. Lowe NJ, Campanati A, Bodokh J, et al. The place of botulinum toxin type $\mathrm{A}$ in the treatment of focal hyperhidrosis. Br J Dermatol. 2004;151:1115-22.

12. Heckmann M, Hyperhidrosis Study Group. Low dose efficacy of botulinum toxin A for axillary hyperhidrosis: a randomized, side-by-side, openlabel study. Arch Dermatol. 2005;141:1255-9.

13. Kranz G, Paul A, Voller B, et al. Long-term efficacy and potencies of botulinum toxin $\mathrm{A}$ and $\mathrm{B}$ : A randomized, double-blind study. Br J Dermatol. 2011;164:176-81.

14. Matarasso A, Matarasso SL, Brandt FS, Bellman B. Botulinum A exotoxin for the management of platysma bands. Plastic Reconstr Surg. 1999;103: 645-52.

15. Ascher B, Zakine B, Kestemont P, Baspeyras M, Bougara A, Santini J. A multicenter, randomized, double-blind, placebo-controlled study of efficacy and safety of 3 doses of botulinum toxin A in the treatment of glabellar lines. J Am Acad Dermatol. 2004;51:223-33.

16. Lowe P, Patnaik R, Lowe N. Comparison of two formulations of botulinum type A for the treatment of glabellar lines: a double-blind randomized study. J Am Acad Dermatol. 2006;55:975-80.

17. Lowe NJ. When and how to combine treatments. In: Lowe NJ, Carruthers A, Carruthers J, et al., editors. Textbook of facial rejuvenation. London: Informa Healthcare; 2002:322-5.

18. Yamauchi PS, Lask G, Lowe NJ. Botulinum toxin type A gives adjunctive benefit to periorbital laser resurfacing. J Cosmet Laser Ther. 2004;6:145-8.

19. Carruthers J, Carruthers A, Maberly D. Deep resting glabellar rhytides respond to BTX-A and Hylan B. Dermatol Surg. 2003;29:539-44.

20. Lowe NJ, Shah A, Lowe PL, Patnaik R. Dosing, efficacy and safety plus the use of computerized photography for botulinum toxins type A for upper facial lines. J Cosmet Laser Ther. 2010;12:106-11.

21. Nettar KD, Yu KC, Bapna S, Boscardin J, Maas CS. An internally controlled, double-blind comparison of the efficacy of onabotulinumtoxinA and 
abobotulinumtoxinA. Arch Facial Plast Surg. 2011; 13:380-6.

22. Sattler G, Callander MJ, Grablowitz D, et al. Noninferiority of incobotulinumtoxinA, free from complexing proteins, compared with another botulinum toxin type $\mathrm{A}$ in the treatment of glabellar frown lines. Dermatol Surg. 2010; 36(Suppl 4):2146-54.
23. Brandt F, O'Connell C, Cazzaniga A, Waugh JM. Efficacy and safety evaluation of a novel botulinum toxin topical gel for the treatment of moderate to severe lateral canthal lines. Dermatol Surg. 2010;36:2111-8. 